\title{
Asta Vrečko
}

\section{Problematika taboriščne umetnosti in Zoran Mušič}

Ključne besede: taboriščna umetnost, Zoran Mušič, slikarstvo, Nismo poslednji

DOI: $10.4312 /$ ars.8.1.213-229

Razprave o umetnosti, ki se navezujejo na tematiko koncentracijskih taborišč in holokavsta, se praviloma začnejo $\mathrm{z}$ ontološkim razmislekom o možnostih reprezentacije. Pregled literature pokaže, da se pri analizi del, ne glede na njihov medij, odpirajo podobna vprašanja. Načini izražanja so izjemno raznoliki ter prihajajo iz različnih spodbud in okolij, zato si bomo najprej ogledali, kaj vse uvrščamo pod to oznako. Ob osnovno začrtanih splošnih dilemah, ki se pojavljajo ob teh delih, bomo $\mathrm{v}$ to poizkusili umestiti dela iz serij grafik in slik s skupnim naslovom Nismo poslednji Zorana Mušiča.

Eden ključnih problemov je možnost upodobitve neupodobljivega. Razmišljanja se velikokrat začnejo z dilemo, ali je trpljenje milijonov, neizmerno človeško krutost na eni in popolno banalnost zla, kot ga poimenuje Hannah Arendt (2007), na drugi strani sploh mogoče upodobiti. Pri analizah se pogosto odpirajo enake moralne dileme, ki so sprva povezane s samo legitimnostjo upodobitve in nato $\mathrm{z}$ njenim načinom, saj tematika po mnenju številnih narekuje še nekaj drugega, nekaj več kot le golo spominjanje dogodkov (prim. Zelizer, 2000; Alphen, 1997). Tudi za Zivo AmishaiMaisels, avtorico ene najbolj celostnih antologij o vplivu holokavsta na vizualno umetnost, kompleksno vprašanje, kako množično ubijanje pretvoriti v umetnost, zaobjema razmislek o poziciji umetnika in gledalca $\mathrm{v}$ zaporedju estetskih in moralnih dilem (Amishai-Maisels, 1993, 34). Pogosta je referenca na znamenit zapis Theodorja Adorna, da je pisanje poezije po Auschwitzu barbarsko (Adorno, 1981, 34). Kljub temu, da nekateri pisci omenjajo kasnejše izjave, v katerih je Adorno poudaril, da je bilo to velikokrat narobe razumljeno, se zdi, da ta misel vendarle simbolno določa tok misli tistih, ki se posvečajo analizi teh del (prim. Weissberg, 2001). Berel Lang se celo sprašuje, ali tema holokavsta morda ne opredeljuje kar svojega žanra (Lang, 2000). V svoji študiji se sicer v veliki meri navezuje na literarni diskurz, vendar lahko podobno prenesemo tudi na vizualno umetnost, s čimer imamo $\mathrm{v}$ mislih vse od tradicionalnih likovnih zvrsti do intermedijske umetnosti. Težko bi pravzaprav našli medij, v katerem se ta motivika ne pojavlja.

Pojav sistematičnega industrializiranega pobijanja in nepredstavljivost množičnih internacij sta zamajala predstave o moderni in civilizacijskem napredku ter zaznamovala 
vso povojno zgodovino. V taboriščih se je uresničilo največje zlo v zgodovini, ki nas je postavilo pred grozljivo vprašanje, ki ni, kako je mogoče, da so bili tako strahotni zločini storjeni, pač pa, prek katerih političnih procedur in dispozitivov so lahko bili udejanjeni. Giorgio Agamben je taborišče utemeljil kot absolutni in nepreseženi biopolitični prostor, utemeljen na izrednem stanju, ki se kaže kot čista paradigma političnega prostora moderne, katerega preobrazbe se moramo naučiti prepoznati (Agamben, 2004; Agamben, 2005). Iskanje različnih odgovorov ter možnosti osmišljenja množičnega uničenja in razčlovečenja je pustilo pečat tudi v umetnosti. Izum koncentracijskega taborišča je sicer starejši od pojava nacističnih in fašističnih taborišč, saj so prva nastala že v 19. stoletju v španskih, ameriških in britanskih kolonijah, vendar v umetnosti niso pustila vidnega pečata. Motivika genocida in internacij tako $\mathrm{v}$ literaturi kot $\mathrm{v}$ vizualni umetnosti in kulturi je postala pogosta šele po drugi svetovni vojni. Tako so se umetniki po drugi svetovni vojni, ne glede na to, da so bili vojni prizori v zgodovini sestavni del umetnostnega imaginarija, znašli pred zadrego, kako množično pobijanje upodobiti. Ernst van Alphen razvije tezo, da gre pri nereprezentativnosti pravzaprav za tehnični problem in pri »tišini« vidi problem semiotske in ne etične narave (Alphen, 1997, 41-42). Problem neupodobljivosti razume v pomanjkanju narativnega okvira, saj se je takšna grozota zgodila prvič in je bilo treba izumiti načine, kako se s tem spopasti tudi na umetnostnem polju (Alphen, 1997, 41-64).

Že iz teh nekaj vrstic je razvidno, da uporabljamo različne besedne zveze bodisi umetnost holokavsta bodisi umetnost taborišč. Jasmina Žgank je v kontekstu literature, in podobno lahko rečemo tudi za vizualno umetnost, opozorila, da kakorkoli opredeljujemo to literaturo, naj bo to »taboriščna«, »koncentracijska« ali "pričevanjska«, jo vedno še dodatno opredeljujemo in uvrščamo v posebno kategorijo, s čimer pokažemo, da nismo več v območju literature. To lahko pomeni, da obstaja dvom glede upravičenosti uvrstitve tovrstne literature v leposlovje, ki med drugim izhaja iz »same nezaupljivosti do pojma »literature«, kadar gre za »resnico« o taboriščih, skratka iz estetskih in moralnih pridržkov« (Žgank, 2008, 6). Ko govorimo o literaturi, poimenovanji "pričevanjska « in »taboriščna « literatura nista enakovredni. Pri pričevanjski literaturi je ena izmed ključnih lastnosti biografskost, pričevalec pa mora biti zaznan kot priča, zato je pripovedovalec praviloma prvoosebni ali vsaj personalni, medtem ko je pri »taboriščni« literaturi največkrat tretjeosebni. Pri pričevanjski literaturi pripovedni liki niso izmišljeni, saj je pripovedovalec zavezan odgovornosti, da ne potvarja realnosti. V primerih, ko je pričevanjski diskurz hkrati literarni, sicer ne moremo pričakovati popolnega ujemanja, a navadno k temu kljub temu stremi (Žgank, 2008, 71).

V zahodni literaturi se najpogosteje pojavlja termin umetnost holokavsta, saj se praviloma navezuje na avtorje, ki so bili zaprti v nacističnih koncentracijskih taboriščih 
ali getih in so judovskega porekla, ali avtorje druge generacije, ki se v delih navezujejo neposredno na holokavst ali nacistična taborišča. Vendar se problematičnost poimenovanja začne že s samim izrazom holokavst, ki pravzaprav nadomešča tehnični termin genocid. ${ }^{1}$ Drugi problem pri tem poimenovanju je, da vsa umetnost, ki je nastajala v taboriščih, tudi umetnost slovenskih avtorjev, ${ }^{2}$ ni povezana izključno $\mathrm{z}$ judovskim genocidom in ni nastajala le $\mathrm{v}$ nacističnih, temveč tudi $\mathrm{v}$ fašističnih taboriščih, ${ }^{3}$ kamor so bili Jugoslovani množično internirani. Ziva Amishai-Maisels je v uvodu v svojo študijo zapisala, da ji dejstvo, da so bili z enakimi metodami internirani in usmrčeni tudi Romi, Rusi, Jugoslovani in pripadniki drugih slovanskih narodov ter ostali »sovražniki« nacionalističnega režima, narekuje, da enakovredno obravnava vse umetnike, ki se ukvarjajo s tematiko nacističnih taborišč v času druge svetovne vojne, saj tudi gola trupla ne izkazujejo narodne identitete in upodobljenih žrtev ter jih $\mathrm{v}$ tem oziru nima smisla razvrstiti v nacionalne skupine (Amishai-Maisels, 1993, xxxiii). Sama se bom, kadar se bom nanašala na vso umetnost, ki je nastala v taboriščih druge svetovne vojne ali je vzela to tematiko za objekt obravnave, posluževala besedne zveze taboriščna umetnost.

Umetnike, ki se ukvarjajo s tematiko taborišč, lahko grobo razdelimo na tiste, ki so internacijo izkusili na lastni koži, in tiste, ki je niso. Med slednje uvrščamo umetnike judovskih korenin, ki so v času vojne živeli v Ameriki in so jih dogodki $\mathrm{v}$ Evropi tako pretresli, da so nanje reagirali z umetnostjo (ki se ni nujno nanašala izključno na holokavst), in judovske umetnike, po vojni delujoče v Sovjetski zvezi. Veliko skupino predstavljajo dela, ki so jih ustvarili umetniki različnega verskega in nacionalnega porekla, ki so se jih grozljivi dogodki globoko dotaknili, vendar tematika

1 Šoah, ki pomeni »opustošenje, katastrofo« in v Bibliji pogosto zajema pojem božje kazni, se uporablja tudi za opis judovskega genocida med drugo svetovno vojno. Izraz holokavst (Holókaustos, gr. »cel sežgan«) v Stari zavezi pomeni žgalno daritev in po Agambenu »izraz ne samo predpostavlja nesprejemljivo primerjavo med krematorijskimi pečmi in oltarji, temveč tudi sprejema semantično dediščino, ki je vse od začetka protijudovsko obarvana« (Agamben, 2005, 24-25). Kot pravi Bauman, je holokavst še ena epizoda v dolgi zgodovini množičnih pobojev, vendar je imel lastnosti, ki jih ni imel noben prejšnji genocid, kar razlaga v kontekstu moderne, saj ga v enaki meri razume kot proizvod in neuspeh moderne civilizacije (Bauman, 2006, 144).

2 V nemških, italijanskih in madžarskih zaporih je bilo petindvajset starejših slovenskih umetnikov z že dokončano akademijo, več kot dvajset takšnih, ki so akademijo končali po vojni, in veliko število samoukov. Iz tega časa se je ohranilo več kot 3500 del, veliko jih je ostalo v tujini, še mnogo več pa je uničenih in izgubljenih (Visočnik, 1969, uvodni tekst). Likovna zbirka Muzeja novejše zgodovine (MNZ) Slovenije hrani okrog 2800 del iz italijanskih koncentracijskih taboriščih in zaporov ter okrog 340 likovnih del iz nemških koncentracijskih taborišč in zaporov.

3 Glavni namen italijanske internacije ni bil identičen kot v nemških taboriščih, saj je bil namen fašistov zlasti deportacija notranjih in zunanjih nasprotnikov režima ter čiščenje nevarnih območij, zlasti na okupiranih ozemljih (Capogreco, 2011, 83). Cilj je bila tudi asimilacija alogenov - tujerodnih, zlasti Slovencev in Hrvatov, živečih na ozemlju, ki je bilo po prvi svetovni vojni priključeno Italiji, in kasneje okupiranih predelih. Tudi po padcu fašizma se položaj interniranih alogenov ni spremenil, protislovanska fašistična politika se je nadaljevala in kljub pozivom $\mathrm{k}$ izpustitvi je po 8. septembru 1943 veliko število internirancev pristalo v rokah nemškega okupatorja (Capogreco, 2011, 107-112). 
ni postala stalnica ali globlje zaznamovala njihovega umetniškega opusa (AmishaiMaisels, 1993, xxxii). Vanjo uvrščamo tudi umetnike druge in tretje generacije, ki izhajajo iz posredovanih spominov in nimajo avtentične izkušnje. Pri obravnavanju njihovih del še bolj intenzivno sledimo nizu moralnih in estetskih vprašanj, ki se dotikajo tako pravice do izrekanja kot estetskih sodb o upravičenosti izbranega medija in umetniškega izraza (prim. Young, 2000; Zelizer, 2001; Hirsh, 2001; Hirsh, 2008).

Posebno skupino sestavljajo umetniki, ki so prebegnili iz okupirane Evrope in so s seboj odnesli spomine na pogrome (praviloma sicer ne taborišča, saj interniranci $\mathrm{v}$ strogo nadzorovanih taboriščih niso imeli možnosti pobega). Videno so skupaj z občutkom krivde, da so zapustili svojce, prijatelje in rojake v Evropi, prenesli v svoje ustvarjanje. Amishai-Maisels $v$ ločeno skupino uvrsti tudi antinacistične oziroma antifašistične propagandiste (Amishai-Maisels, 1993, xxxii). Ti, navadno komunisti, so se proti fašizmu borili že od zgodnjih dvajsetih let dalje in so problematiko taborišč umeščali v okvir boja proti vojni (Amishai-Maisels, 1993, xxxii).

Med tistimi, ki so sami preživeli taborišča, so bili nekateri že pred internacijo likovno izobraženi in so delovali kot umetniki, drugi pa so bili samouki ali so se $\mathrm{z}$ risanjem začeli ukvarjati tam. $\mathrm{V}$ taboriščih se je praviloma ustvarjalo na skrivaj, tudi za ceno življenja. V vlogo kronistov taboriščnega življenja je večino potisnila želja, da to nesmiselno trpljenje ne bi utonilo v pozabo. Številni pričevalci govorijo o tem, da so se z ustvarjanjem na duhovni ravni upirali nacistični dehumanizaciji in se borili za ohranitev osebne identitete v razmerah, ko jim je bila popolnoma odvzeta, saj je bila razlastitev subjekta njegovih lastnosti cilj procesa ob vstopu v ujetništvo. In »ko so človeški objekti birokratskega postopka učinkovito razčlovečeni in torej izničeni kot potencialni subjekti moralnih zahtev, je nanje mogoče gledati z etično brezbrižnostjo« (Bauman, 2006, 165). Po mnenju Viktorja E. Frankla, psihologa in interniranca, so tisti, ki so pred tem živeli duhovno bolj razgibano življenje, lažje prenašali to novo situacijo, saj so se lahko iz strašnega okolja umaknili v notranje kraljestvo duhovne svobode (Frankl, 1992, 32-33).

$\mathrm{V}$ to skupino uvrščamo tako tiste umetnike, katerih dela imamo ohranjena iz taborišč, kot tiste, ki so se k tematiki vrnili kasneje. Stane Mikuž je risbe, ki so nastale v taborišču, razdelil v dve podskupini, na dela, nastala pred osvoboditvijo, in dela, nastala po njej. $\mathrm{V}$ času po osvoboditvi so bili ujetniki iz različnih razlogov (zlasti zdravstvenih in organizacijskih) prisiljeni ostati $v$ taborišču še nekaj časa, preden so bili dokončno izpuščeni. A znotraj njega so se lahko svobodno gibali in tako uzrli nekatere prizore, ki so jim bili do tedaj prikriti, kot je na primer pogled v notranjost krematorija. Tudi videz taborišča se je spremenil, saj so bila trupla nakopičena vsepovsod (Pirnovar, 1999, 57, 61). Nace Šumi je dodal še ločnico po 
motiviki, saj je bilo po osvoboditvi taborišče mogoče videti in upodobiti še iz drugih perspektiv - na primer pogled iz opazovalnih stolpov ipd. ${ }^{4}$ Čeprav s taboriščno umetnostjo skoraj vedno mislimo na zgoraj omenjena dela, je treba opozoriti še na druge vloge umetnosti v taboriščih, ki niso bile nelegalne. Iz slovenske zgodovine se lahko spomnimo na italijansko taborišče Gonars, v katerega je bilo interniranih največ slovenskih slikarjev. V njem je bila poleti 1942 približno dva meseca organizirana slikarska šola, katere pobudnik je bil slikar Nikolaj Pirnat. Obiskovalo jo je dvajset do trideset mlajših slikarjev in samoukov, ki so priredili tudi razstavo (Visočnik, 1969, uvodni tekst). Pirnatu je poveljnik taborišča zaupal celo izdelavo Marijinega kipa. V Gonarsu so občasno organizirali kulturne prireditve, ujetniki pa so tiskali glasilo Izza žice. Takšne dejavnosti so bile prepovedane, potem ko je Osvobodilna fronta v noči na 31. avgust 1942 organizirala pobeg nekaterih svojih najbolj ogroženih članov (Capogreco, 2011, 231-232). V zgodnjih fazah so tudi v nekaterih nemških taboriščih prirejali razstave. Vso razstavljeno uradno umetnost taborišč je seveda naročilo in odobrilo vodstvo (Costanza, 1984, 14). Osnovna naloga naročene umetnosti je bila, da je tamkajšnje življenje prikazovala kot znosno, celo prijetno, s čimer je pripomogla $\mathrm{k}$ ustvarjanju boljše javne podobe. Ti umetniki so imeli zaradi izvrševanja uradnih naročil omogočen dostop do risarskega materiala in so lahko stran od pogledov stražarjev upodabljali neolepšano podobo taborišč. ${ }^{5}$ Interniranci so izvrševali vse od propagandističnih uradnih naročil do manjših osebnih naročil, kot so bili portreti ali risbe po fotografijah, ki so jih pazniki imeli za spomin na svojce ali jih pošiljali domov svojim družinam, ujetniki pa so s temi uslugami pridobili material za ustvarjanje ali prepotrebna dodatna živila. Nekateri so bili v nacističnih taboriščih zaradi svojega znanja prisiljeni v izdelovanje različnih ponaredkov dokumentov in kopij umetniških del (Costanza, 1984, 23-51, 94-98). Pričevanja o dogajanjih v taboriščih, ki so ponudila pogled v preživeto izkušnjo, so praviloma prišla z zakasnitvijo (LaCarpa, 1998, 11). Vrnitev k tematiki taborišč v umetniških opusih je pogosta $\mathrm{v}$ šestdesetih in sedemdesetih letih prejšnjega stoletja (Amishai-Maisels, 1993, 94). V taborišču so se interniranci znašli v nerazumljivem

4 Stane Mikuž in Nace Šumi sta se pri svoji analizi navezovala tudi na lastno izkušnjo, saj sta bila oba internirana v Dachauu. Risbe iz prve skupine, torej tiste, ki so bile ustvarjene pred osvoboditvijo taborišča 29. aprila 1945 in so nastale na skrivaj, ko je bilo upodabljanje dachavske resničnosti smrtno nevarno, saj je bilo razumljeno kot vohunstvo, so bile bolj redke. Največ likovnih pričevanj iz nemških taborišč je nastalo tik pred osvoboditvijo, ko ni bilo več enakega rigoroznega nadzora, velika večina pa ob oziroma po osvoboditvi (Mikuž, 1985, uvodni tekst; Šumi, 1999, 107-108; Visočnik, 1969, uvodni tekst). Seveda obstajajo izjeme. Dela slovenskega arhitekta Vlasta Kopača, ki je bil v Dachauu zaprt kar šestnajst mesecev, so večinoma nastala v času pred osvoboditvijo. Po njej se je skoraj izključno posvetil izdajanju slovenskega osvobodilnega časopisa Dahavski poročevalec (Haibl, 2012, 40-49).

5 Koncentracijsko taborišče v Terezinu (tudi Theresienstadt Ghetto) je imelo pomembno propagandno vlogo in razvito kulturno življenje. Ujeti umetniki so za obiske Rdečega križa redno pripravljali zavajajoča dela in hkrati na skrivaj upodabljali realnost prenatrpanega geta. Ti so ena najprepoznavnejših skupin taboriščnih umetnikov (Costanza, 1982). 
svetu, kjer so bile meje med taboriščniki zabrisane, posameznikova identiteta se je izgubljala in okolje ni dopuščalo veliko prostora za moralne odločitve. Postavljeni nazaj v »normalno« življenje so se začeli zavedati, kje so bili in kako so tam (pre) živeli. Tem občutjem se je pridružila še žalost zaradi pogrešanih svojcev, izčrpanosti in opustošenja, ki ga je pustila vojna v pokrajini, mestih in srcih ljudi, kar je lahko bil eden izmed razlogov, zakaj so se neposredno po vojni nekateri zavestno odločili, da bodo to izkušnjo raje pozabili (Levi, 2003).

Pojav holokavsta in taborišč $\mathrm{v}$ umetniških opusih je povezan tudi s sočasnim družbeno-političnim dogajanjem. $\mathrm{V}$ času, ko se je zdelo, da je zahodni svet pozabil na nedavno preteklost, so se $\mathrm{v}$ svetu ponavljale grozote, ki so jih preživeli iz druge svetovne vojne dobro poznali. Povezave med nacističnimi taborišči ter kasnejšimi žrtvami vojnega nasilja in genocidov so bile prav tako pomemben del umetnosti proti vietnamski vojni. Kot je zapisal Alphen $(1997,94)$, integracija preteklosti s sedanjostjo pri teh umetniških delih tako ni redka, saj ne glede na to, da dogodki sicer pripadajo preteklosti, izkušnje ostajajo.

Iz začetnega vprašanja, ali je upodobitev nečesa tako strašnega sploh mogoča, izhajajo tudi druga, ki se pojavljajo skoraj enako pogosto. Ta povezujejo moralne in stilistične dileme ter izhajajo iz frustracije v motiviki, torej kaj upodobiti, da bo primerno predstavljalo smrt milijonov. Temu praviloma sledijo razmisleki o tem, na kakšen način je to mogoče narediti: ali se odločiti za realizem in se približati veristični upodobitvi dogodkov ali subjektivizirati realnost. V številnih razpravah estetsko doživljanje in transmisija zgodovinske vednosti nista razumljena dialektično, ampak kot nasprotujoči si poziciji. Moralna vprašanja, ki se odpirajo, pa praviloma vzpostavljajo dihotomijo med zgodovinskim in bolj imaginativnim diskurzom, ${ }^{6} \mathrm{ki} \mathrm{je}$ v umetnosti sicer zaželen, vendar ga pri tej tematiki pogosto spremlja dvom (Alphen, 1997, 16-37). V svoji študiji je Amishai-Maisels ugotovila, da je v času internacije večina umetnikov taboriščno življenje upodabljala realistično. So se pa pojavljale razlike, in to ne zgolj med različnimi umetniki, pač pa tudi med obravnavo različnih tematik pri posameznem umetniku. Odločitev za spremembo umetniškega izraza je lahko pri nekaterih, ki so se v svojem opusu k tematiki še vračali, prišla tudi pozneje (Amishai-Maisels, 1993, 6-7). In če že iščemo odgovor na vprašanje, kateri stil je pri upodobitvah holokavsta ustrezen, simbolizem, realizem ali abstrakcija, je zanj med drugim pomembno, kdo je umetnik in kakšni so njegovi razlogi za izbiro tematike (Amishai-Maisels, 1993, xxxii).

6 Susan Sontag, ki se ob tem vprašanju osredotoči na primer fotografije, ugotavlja, da je, medtem ko je v likovni umetnosti vse dovoljeno in lahko tudi v upodobitvah najhujših možnih grozot iščemo lepoto in estetsko zadoščenje, medij fotografije v tem primeru navadno soočen $\mathrm{z}$ obsojanjem, saj naj bi bila fotografija posnetek realnega stanja in usmerjena na dokumentarnost (Sontag, 2006, 71-78). 
Zoran Mušič (1909-2005) je eden izmed najbolj znanih slovenskih umetnikov, ki je del svojega opusa posvetil opisanim tematikam in ima v ikonografiji holokavsta posebno mesto. Med izjemno pomembne avtorje ga umeščata Ziva Amishai-Maisels (1993) in Mary S. Costanza (1982), avtorici dveh najpreglednejših študij o taboriščni umetnosti.

Mušič se je rodil v Bukovici v Spodnji Vipavski dolini in slikarstvo študiral na akademiji v Zagrebu, kjer je diplomiral leta 1934 ter študij nadaljeval še v dveh podiplomskih semestrih. V začetku oktobra 1944 ga je v Benetkah aretiral gestapo in novembra je bil že odpeljan v Dachau. Po osvoboditvi se je za kratek čas vrnil v Ljubljano in nato odšel v Italijo. Preostanek življenja je prebival v Benetkah in Parizu, a se je po letu 1956, ko so mu odobrili vizum, redno vračal v domovino (Zupan, 2009; Zupan, 2012).

V Dachauu je Mušič s pomočjo sojetnika dobil delo v podzemni tovarni streliva. Zaradi popuščanja discipline $\mathrm{v}$ taborišču proti koncu vojne je prišel do papirja in začel skrivoma risati. Občasno je portretiral tudi stražarje ali njihove bližnje, ki so mu priskrbeli slikarske pripomočke. Za paznike je poslikaval senčnike za luči z motivi Benetk in s prizori iz oper. Portretiral je tudi oficirja in zanj prerisal nekaj razglednic (Zupan, 2009, 202). Nedovoljene risbe je iz bojazni pred kaznijo sproti uničeval, nekaj pa jih je skril v stroj v tovarni, kjer je delal, a so bile po osvoboditvi skupaj s tovarno uničene (Zupan, 2009, 203). Kot so se spominjali tudi drugi, ki so ustvarjali v taboriščih, in je razložil tudi Viktor Frankl (1992), je bilo od teh risb odvisno tudi Mušičevo življenje (Costanza, 1982, 61). Od 30. aprila do 5. junija, ko je lahko odšel domov, so nekdanji interniranci imeli dovolj materiala, da so lahko upodabljali taborišče - $\mathrm{v}$ tem času je nastala tudi večina Mušičevih ohranjenih del iz Dachaua (Zupan, 2009, 203).

Dela slovenskih slikarjev, ustvarjena v internaciji, praviloma niso imela statusa samostojnih umetnin, ampak dokumentarnega gradiva. Obžalovanje nad takšno podcenjevalno obravnavo je izrazil Nace Šumi, ki je zapisal, da pri teh risbah ne gre zgolj za ustvarjanje "nekih neosebnih 'dokumentov' ", in poudaril, da lahko ta dela »štejemo med umetniške izdelke $\mathrm{z}$ izrazito avtorsko noto, po kateri lahko brez težave prepoznavamo posamezne ustvarjalce« (Šumi, 1999, 107-108). Tudi to opažanje potrjuje omenjeni problem, da ta dela niso deležna enake obravnave kot druga umetniška dela, saj so podvržena drugačnim kriterijem. Zanje se, kakor je razvidno iz Šumijevega razmišljanja, predpostavlja, da morajo biti nosilci dokumentarnega zgodovinskega pričevanja, kar praviloma izključuje, kakor je ugotavljal Alphen, razmišljanje o njihovi umetniški vrednosti. Pri tem so risbe Zorana Mušiča izjema, saj jih je redno umeščal v svoje razstave in so bile tako deležne drugačne obravnave.To 
potrjuje tudi dejstvo, da so njegove risbe večinoma hranjene v umetnostnih zbirkah. ${ }^{7}$ V Sloveniji jih, razen ciklostila $\mathrm{v}$ dveh odtisih, ki sta $\mathrm{v}$ Muzeju novejše zgodovine $\mathrm{v}$ Ljubljani, hrani Moderna galerija v Ljubljani (Zgonik, 2012, 136).

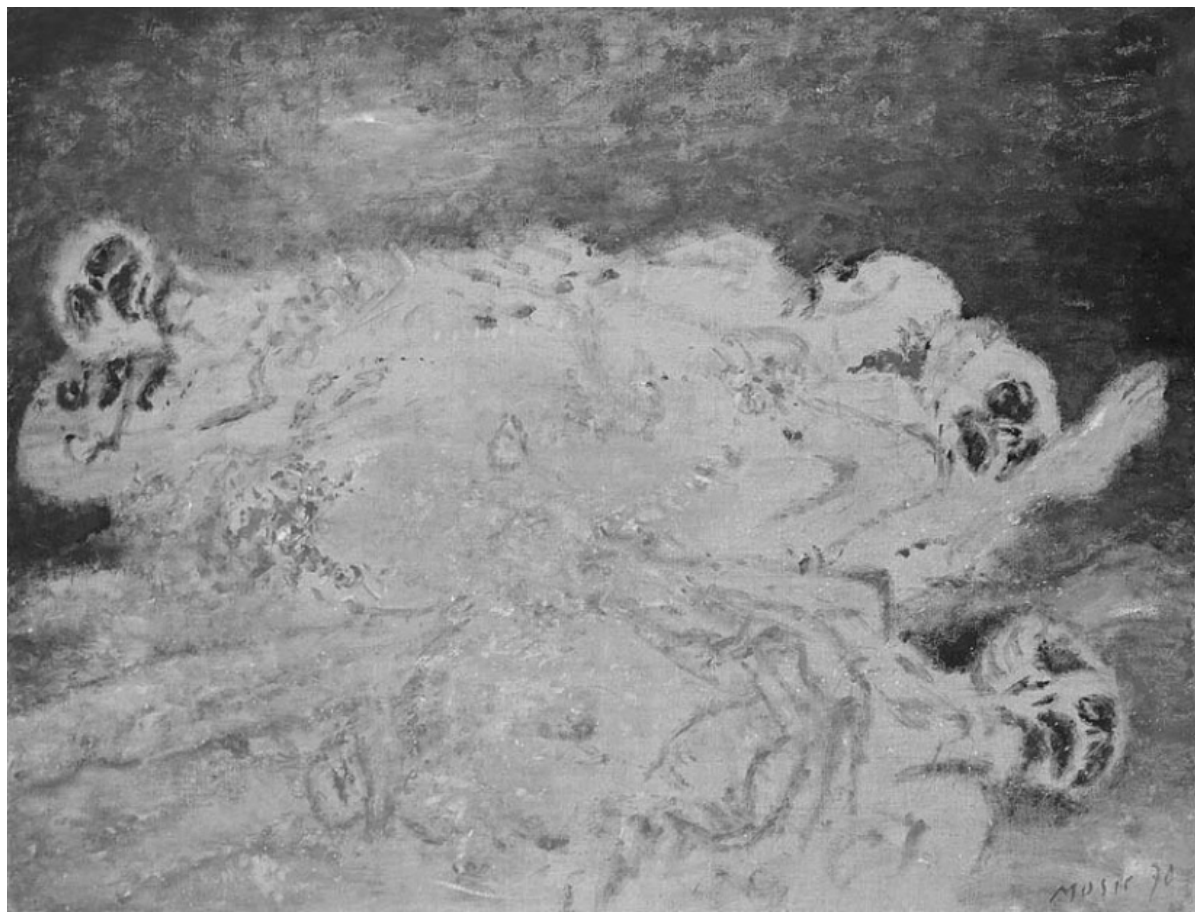

Slika 1: Zoran Mušič, Dachau, 1945, tuš na papirju, 33,5 x 47,8 cm, Moderna galerija, Ljubljana, inv. št. MG 238/R. Foto: L. Mlekuž.

Abstraktna umetnost je bila v kontekstu reprezentacije holokavsta bodisi odgovor na njegovo neupodobljivost in služila kot vzpostavitev distance do motiva (Bartov, 1996) bodisi je pomenila odpoved motiviki taborišč v imenu pozabe na dogajanje med vojno in povratek nazaj v normalno življenje. Ko so se umetniki, ki so se po vojni odločili za izražanje v abstrakciji, vrnili k tematiki holokavsta, to pogosto ni bila več abstrakcija (Amishai-Maisels, 1993, 243-244). To velja za Mušiča, saj je tematika Dachaua v njegov opus vstopila v sedemdesetih letih, torej po abstraktni slikarski fazi. Ciklus grafik in platen, ki jih je naslovil s skupnim naslovom Nismo poslednji, je v presledkih ustvarjal od leta 1970 do leta 1988. Medtem ko je risbe iz taborišča razstavljal že pred tem, se v povojnem opusu k motiviki vse do tega trenutka ni vračal. To je razlagal z bojaznijo, da bi pod neposrednim vtisom doživetega lahko nastala

7 Ocene, koliko risb je ustvaril v Dachauu, se razlikujejo in variirajo med sto in dvesto. Gojko Zupan meni, da so Mušič in njegovi prijatelji iz taborišča odnesli okoli sto risb in grafičnih odtisov, od katerih je znanih ohranjenih osemdeset. Točnega števila ohranjenih risb iz Dachaua v evropskih in svetovnih zbirkah ne poznamo. Za natančen popis znanih risb iz Dachaua glej Zupan 2009. 
zgolj ilustracija videnega. ${ }^{8}$ Jean Améry, rojen Hans Maier, nekdanji taboriščnik, filozof in pisatelj, je zapisal, da kdor je bil mučen, ostane mučen vse življenje, ter da kdor je pretrpel mučenje, se ne more več prilagoditi temu svetu, saj ga ta izkušnja spremlja in si ne more več pridobiti zaupanja v človeštvo (Levi, 2003, 18). Mušič je dejal, da je Dachau ves čas nosil v sebi. Pri ustvarjanju del iz ciklusa Nismo poslednji si ni pomagal z risbami iz Dachaua (Brejc, 2012, 72). Pri grafikah se zaradi risarske poteze povezava med njimi sicer zdi bolj očitna kakor pri platnih, vendar gre v obeh primerih za njegovo ponotranjeno interpretacijo videnja odhajajočega življenja ter osebno doživljanje skrajnih meja obstoja in ne za povzemanje po risbah, ki bi mu v tem primeru služile kot zgodovinski dokument.

Ko se je Mušič po povojni abstraktni fazi vrnil k pokrajini, se je ta spremenila skoraj sinhrono z obuditvijo taboriščne tematike in dobila pridih antropomorfnosti. To lahko opazimo tako pri ciklih Skalnatih pokrajin, Kamenja (po letu 1969) kot v ciklu Rastlinski motivi, ki je nastajal vzporedno s ciklusom Nismo poslednji, med letoma 1972 in 1975. Na njih opazujemo osušene ostanke nekoč mogočnih dreves, preperela debla, ki so mestoma rahlo usločena kot nepremična telesa, iz katerih štrlijo veje proti tlom kot mrtvi, težki udi.

V seriji del Nismo poslednji so upodobljene človeške figure v smrtni agoniji ali že mrtve. Pojavljajo se samostojno, v parih, skupinah ali v nepregledni množici, v kateri se trupla zlijejo $\mathrm{v}$ nerazpoznavno gmoto, tako da posameznih teles ni mogoče ločiti drugo od drugega. Arhetip izmučenega in do kosti izžetega obraza se v ciklusu ves čas ponavlja in nikoli ne dobi bolj portretnih značilnosti. Prav tako se ponavlja barvna lestvica, ki je razmeroma skopa in razen nekaterih odstopanj zavezana zemeljskim tonom. V njegovem opusu je na neki točki ozadje prenehalo biti v celoti poslikano in v prvi plan so stopile zaplate surovega platna, ki jih lahko v tej seriji prav skozi njeno negacijo razumemo kot zgodovinsko referenco.

Čas nastanka prve serije Nismo poslednji sovpada $\mathrm{z}$ množičnim pojavom omenjene spominske literature in reminiscenc umetnikov na obdobje druge svetovne vojne. Potlačen spomin na preživete grozote je privrel na dan ob neljubi spodbudi sočasnega družbeno-političnega dogajanja, ki je prispevalo k spoznanju, da se zlo ponavlja. Amishai-Maisels Mušiča v tem oziru primerja $\mathrm{z}$ umetnikoma Hymanom Bloomom in Leonardom Baskinom, ki sta že pred njim prišla do podobnih zaključkov in to povezavo vzpostavila v svojih umetniških delih (Amishai-Maisels, 1993, 94-96). Povezavo je v kontekstu razlogov za vračanje k tej tematiki poudarjal

8 "Vedel sem, da je v meni Dachau, ampak če bi takrat, še pod neposrednim vtisom začel slikati, bi lahko nastala le ilustracija. Ilustracija pa je lahko v slikarstvu le nezgoda, in to največja. No, v meni je to vrelo in vrelo in nekega dne, leta 1970 je bilo, če se ne motim, v sedemdesetih letih, vsekakor - je prišla prva reč $\mathrm{s}$ to temo na dan. Potem je bilo vse odprto, odprta je bila pot grmadam mrtvecev in tako naprej« (Hudeček, 2001, 20). 
tudi Mušič sam: »Biafra, Vietnam, Latinska Amerika, Stalinova Rusija - eno izhaja iz drugega, čeprav so metode različne. Zame človeštvo ni nič boljše kot včeraj. Priče smo istega trpljenja. Tudi v teh slikah se vračam k nečemu, kar je vedno prisotno in nesprejemljivo, kot kraška zemlja, ki je komaj živa, a vendar obstaja, vedno enaka, ne glede na letni čas. Nismo zadnji ni samo Dachau, to ni navaden polemični prispevek. To je vselej prisotna mora, nesprejemljiva, vedno enako preteča (Kolšek, 1995, 30). Vendar pri Mušiču, ki je bil za razliko od nekaterih drugih umetnikov izrazito apolitična figura, ne gre za politični protest, temveč za izraz globokega razočaranja nad družbo ter humanistični protest proti nečloveškemu ravnanju (Amishai-Maisels, 1993, 353; Brejc, 2012, 73).

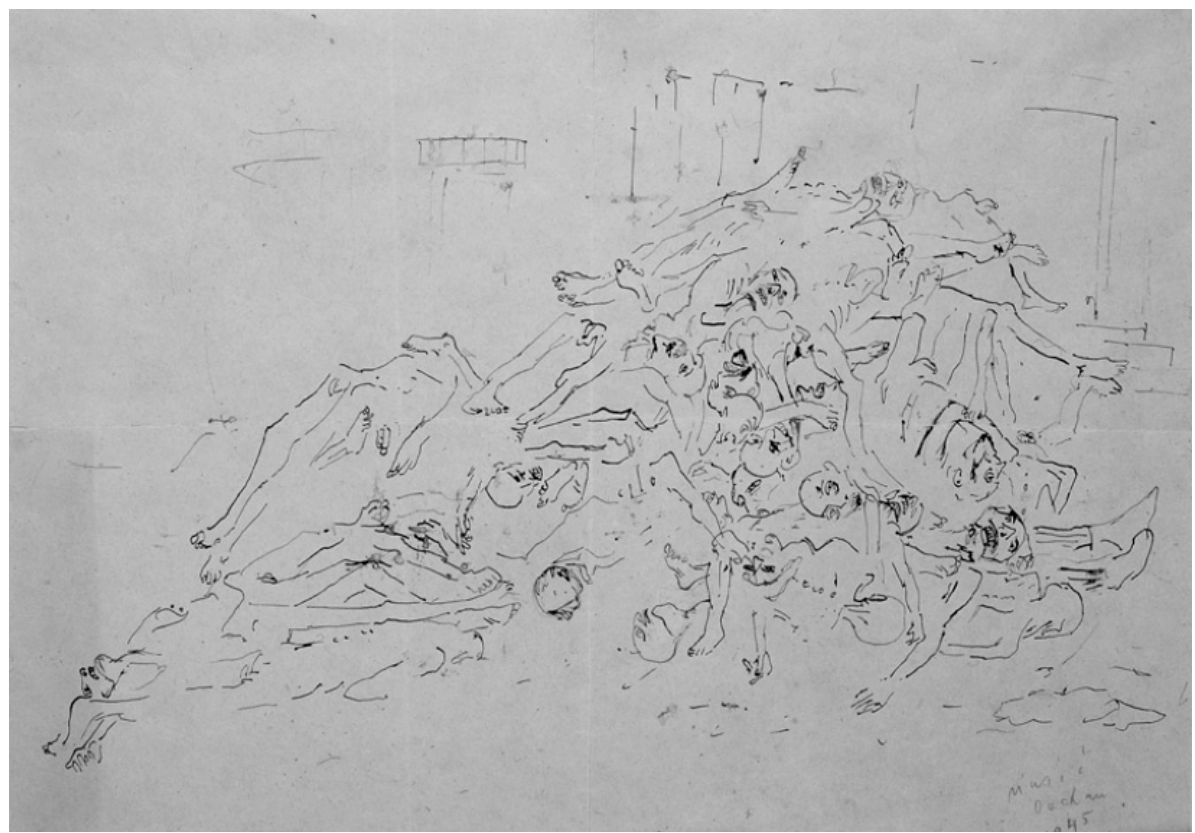

Slika 2: Zoran Mušič, Nismo poslednji, 1970, olje na platno, 114 x 146,5 cm, Moderna galerija, Ljubljana, inv. št. MG 795/S. Foto: L. Mlekuž.

Pri iskanju odgovora na vprašanje, kako sploh upodobiti nekaj tako grozljivega, kot je sistematično pobijanje ljudi, se je, kot piše Amishai-Maisels, veliko umetnikov naslonilo na Francisca Goyo in upodabljalo prizor od blizu, kakor je on počel v grafikah (Amishai-Maisels, 1993, 42), zlasti v ciklu dvainosemdesetih jedkanic s skupnim naslovom Grozote vojne (Los desastres de la guerra, 1812-1815), ${ }^{9}$ posvečenem

9 Raziskovalci so kolekcijo razdelili na tri velike cikle: do grafičnega lista 47 so vojni prizori, od 48 do 64 prizori lakote v Madridu, od 65. lista dalje pa zanosne fantazije (fantazija pri Goyi označuje različnost vsebine, prehajanje iz enega v drug svet na podlagi notranjega razmerja). Ohranjenih je tudi šestinpetdeset pripravljalnih risb. Iz tega časa je poznan le en natisnjen primerek. Prvič so bile objavljene leta 1863 , petintrideset let po njegovi smrti. Gre za jedkanice, ponekod pa si je 
krvavim zločinom Napoleonove vojske, ki je leta 1808 napadla Španijo, da bi zadušila upor proti francoskim oblastem. Pred tem so bile vojne in njihove posledice praviloma upodobljene s strani zmagovalca. Pri teh grafikah pa je vse veličastno in vzvišeno odstranjeno, tudi pokrajina je nakazana zgolj v obrisih. Ostalo je le bistveno, kot pove že naslov, grozote vojne. Vojna ni prikazana kot gledališki spektakel in te grafike niso, niti se ne trudijo biti, pripovedne, kar kasneje postane novo merilo dovzetnosti za trpljenje žrtev vojne. Zoran Mušič je že iz časa študija zelo dobro poznal špansko slikarstvo in Goyo, saj je v Zagrebu slikarstvo študiral pri profesorju Ljubi Babiću, ki je študente spodbujal k študiju francoskega in španskega slikarstva (Brejc, 2012, 42-43). Konec marca 1935, ko je dobil štipendijo Narodne galerije, se je za dobre tri mesece odpravil na študijsko potovanje v Španijo (Zupan, 2009, 197). Iz tega časa je ohranjen pomemben del gradiva, tudi kopije Goye in El Greca (Zupan, 2012, 252). O vplivu Goye na njegovo slikarstvo je govoril tudi sam: »Ah, Goya, njega takrat (na potovanju v Španijo, op. a.) še nisem prav razumel. To je prišlo za menoj šele po Dachauu. Šele potem sem vedel, kaj je pravi Goya« (Hudeček, 2001, 18).

Tako kot so prvi vojni fotografi pod svoje fotografije dodali naslove za opis dogajanja, je že Goya z napisi pod grafikami še dodatno poudaril pomen in nas opozoril na bistvo upodobljenega (Sontag, 2006, 41-44). Mušičev naslov ciklusa Nismo poslednji že sam po sebi napeljuje na nekaj več kot zgolj upodobitev zgodovinskega dogodka. Gre za komentar, ki prav tako kot pri Goyi opozori na bistvo upodobljenega. Kot je razložil sam: »In potem smo videli, da nismo bili zadnji. Takrat je bil Vietnam«(Kolšek, 1995, 30). Naslov opozarja na večno ponavljanje zla in s tem zanika vzklike internirancev ob osvoboditvi »Mi smo zadnji!«. Naslov ciklusa $z$ nagovorom v prvi osebi množine odpira tudi problematiko, ki se znotraj diskurza o taboriščni umetnosti pogosto pojavlja, to je problematika priče in pričevalca.

Po Leviju je prava priča le tisti, ki je nečlovek, tisti, ki je absolutno nezmožen pričati. Pravim pričam, tistim, ki so doživeli dokončno uničenje vsakršne človeškosti, je bila odvzeta zmožnost pričevanja, a ti ne bi pričali, »čeprav bi imeli papir in pero, saj so umrli, še preden je umrlo njihovo telo. Že tedne in mesece pred smrtjo so izgubili sposobnost opazovanja, pomnjenja, primerjanja in izražanja. Namesto njih govorimo mi kot njihovi pooblaščenci.« Pričevanje o tej skrajni usodi je lahko le »pripoved 'v imenu tretjih oseb', pripoved o stvareh, ki smo jih videli od blizu, nismo pa jih doživeli« (Levi, 2003, 66). Tako pravzaprav nihče ne more govoriti o skrajni usodi, ki potisne človeka na rob in iz katere ni povratka, ko je človek le še po imenu, skorajda ne več niti po videzu niti razmišljanju. V taboriščih so te ljudi,

pomagal tudi s suho iglo ali dletom (Parrondo, 1993, 10-12). Prim. Dieterich, 1972, 18-20 - omenja dvainsedemdeset pripravljalnih risb. 
ki so bili nepovratno izčrpani, onemogli in blizu smrti, imenovali Muselmann, $»$ musliman $\aleph^{10}$ (Levi, 2003, 79).

Za Amishai-Maisels je v ciklu Nismo poslednji najbolj grozljivo dejstvo, da so upodobljeni še vedno živi (1993, 95-97). Tudi Mušiča je ugotovitev, da so kupi trupel še vedno živi, pretresla, ko je neke noči ugotovil, da zvok, ki ga je slišal ponoči, ni nastal zaradi vetra, ampak je slišal vzdihovanje gomile ljudi, ki so čez noč umrli (Hudeček, 2001, 20).

Podobe, ki jih vidimo na upodobitvah v ciklusu Nismo poslednji, ne spadajo ne v svet živih ne mrtvih. Čeprav so postavljene pred prazno ozadje in jih ne definira nobena zgodovinska referenca, takoj vemo, kam spadajo. Brez dvoma sodijo v repertoar taboriščne umetnosti. "Če bi lahko z eno samo podobo zajel vse zlo našega časa, bi izbral to, tako domačo podobo: mršav mož z nagnjenim čelom in ukrivljenimi rameni, na čigar obrazu in očeh ni moč razbrati niti sledu kakšne misli, « je o »muslimanih" zapisal Primo Levi (Levi, 2004, 79). Osebe na Mušičevih platnih zrejo prazno in nepremično, njihova mrtva telesa, tudi tista, ki se še oklepajo zadnje trohice življenja, ne morejo povedati zgodbe same. $Z$ njihovo upodobitvijo si je umetnik zadal nalogo, da bo zgodbo povedal namesto njih, ali morda bolje, skupaj z njimi. Med ta (pol)trupla, ki so se v opusu pojavila kot interpretacija spominov na videne in doživete grozote $\mathrm{v}$ taboriščih, se je vendarle nekako umestil in s tem jasno utemeljil pozicijo, iz katere se o teh dogodkih izjavlja. Čeprav dela niso moralizirajoča, nosijo v sebi tudi etični imperativ. Kljub temu, da se jasno navezujejo na taborišča druge svetovne vojne, opominjajo na sočasne in prihodnje grozote, do katerih lahko pripelje napačna ideologija.

Iskati lepoto znotraj ikonografije holokavsta je delikatno področje, a vendar $\mathrm{v}$ Mušičevih delih ne moremo zanikati estetike. Miklavž Komelj vidi razlog, zakaj so lahko ta trupla upodobljena s takšno estetizacijo, a se nam te nemogoče podobe še vedno ne zdijo obscene, prav v umetnikovi izkušnji v Dachauu (Komelj, 2009, 172). Pri tej konfliktnosti pa ne gre za zmago lepote nad grozo, ampak do skrajnosti prignano konfliktnost, ki pa je prav tisto, kar te podobe naredi estetsko sprejemljive (Komelj, 2009, 176).

Zorana Mušiča lahko umestimo v pričevanjsko umetnost, saj tudi naslov ciklusa Nismo poslednji v prvi osebi množine nakazuje, da nam pripoveduje svojo preživeto zgodbo. Vsakršno govorjenje o portretih ali prikritih avtoportretih pri teh delih bi bilo pretiravanje, saj so obrazi prignani do poslednje meje razpoznavne človeškosti, brez individualnih lastnosti, a hkrati je nemogoče trditi, da je sebe izvzel iz upodobljenega.

10 Zakaj se je tem ljudem na robu življenja reklo tako, obstajata dve razlagi: fatalizem in povoji na glavi, ki bi lahko spominjali na turban, a sta obe, kakor piše Levi, neprepričljivi (Levi, 2003, 79). Agamben pravi, da obstaja še dodana, a tudi ne najbolj verjetna razlaga, da bi lahko bilo takšno poimenovanje tudi aluzija na besedo »Muschelmann, človek školjka, tj. uvit in zaprt sam vase« (Agamben, 2005, 33). 
Umetnikov opus se je zaključil s starostnimi avtoportreti. Ti so ekspresivni, v njih pa lahko najdemo nekatere poteze ter uporabo barve, zlasti bele, ki je bila pred tem rezervirana za mrtvake iz taborišč. To nas napelje na misel, da je v pozni starosti tudi sam postal ta priča, nezmožna pričati, namesto njega pa sedaj govorijo njegova dela.

\section{Literatura}

Agamben, G., Homo sacer, Suverena oblast in golo življenje, Ljubljana 2004.

Agamben, G., Kar ostaja od Auschwitza, Arhiv in priča (Homo sacer III), Ljubljana 2005.

Alphen, E. van, Caught by History. Holocaust Effect in Contemporary Art, Literature, and Theory, Stanford 1997.

Amishai-Maisels, Z., Depiction and interpretation, The influence of Holocaust on the visual arts, Oxford 1993.

Arendt, H., Eichmann v Jeruzalemu, Ljubljana 2007.

Adorno, T., Cultural Criticism and Society, Prisms, Cambridge 1981.

Bartov, O., Murder in Our Midst, The Holocaust, Industrial Killing and Representation, New York 1996.

Bauman, Z., Moderna in holokavst, Ljubljana 2006.

Brejc, T., Zoran Mušič in slikarska tradicija, v: Videnja Zorana Mušiča (ur. Grafenauer, N., Puhar, A., Zupan, G.), Ljubljana 2012, str. 38-80.

Capogreco, C. S., Fašistična taboričča: internacije civilistov v fašistični Italiji (19401943), Ljubljana 2011.

Costanza, S. M., The Living Witness, Art in the Concentration Camps and Ghettos, New York 1982.

Kolšek, P., Zakaj bi moral človek ven, če ima svet v sebi, Delo, 29. julij 1995, str. 30.

Komelj, M., Mušič in meja podobe, v: Zoran Mušič v javnih in zasebnih zbirkah v Sloveniji (ur. Ilich-Klančnik, B., Soban, T.), 24. november 2009-28. februar 2010, Moderna galerija, Ljubljana 2009, str. 170-177.

LaCapra, D., History and Memory after Auschwitz, New York 1998.

Dieterich, A., Goya, Visionen einer Nacht, Zeichnungen, Köln 1972, str. 7-35.

Frankl, V. E., Kljub vsemu rečem življenju da, Psiholog doživi taborišče smrti, Celje 1992.

Haibl, M., Zamajani pogled: risbe Vlasta Kopača iz koncentracijskega taborišča Dachau (1944-1945) (ur. Širok, K., Šparovec, J., Lesjak, D.), 27. april-2. september 2012, KZ-Gedenkstäte Dachau, Dachau in 1.-30. junij 2013, Muzej novejše zgodovine Slovenije, Ljubljana 2012, str. 40-49. 
Hirsch, M., Surviving Images: Holocaust Photographs and the Work of Postmemory, v: Visual Culture and the Holocaust (ur. Zelizer, B.), New Brunswick 2001, str. 215-246.

Hirsch, M., The Generation of Postmemory, Poetics Today 29 (1), 2008, str. 103128.

Hudeček, J., Izmaknil sem se jim zadnji hip. Pogovor z Zoranom Mušičem, Ampak, 6. april 2001, str. 18-23.

Lang, B., Holocaust Representation. Art within the Limits of History and Ethics, Baltimore 2000.

Levi, P., Ali je to človek, Premirje, Ljubljana 2004.

Levi, P., Potopljeni in rešeni, Ljubljana 2003.

Mikuž, S., Dachauske risbe, Likovna dela slovenskih jetnikov $v$ nacističnem koncentracijskem taborišču Dachau iz obdobja od januarja 1944 do junija 1945 (ur. Durjava, I.), 6. november-25. december 1985, Muzej ljudske revolucije Slovenije v Ljubljani, Ljubljana 1985.

Pirnovar, H., Dachau, Fotografije in risbe iz koncentracijskega taborišča s komentarjem (ur. Pirnovar, H.), Celje 1999.

Sontag, S., Pogled na bolečino drugega, Ljubljana 2006.

Šumi, N., Dahavske risbe, Dachau, Fotografije in risbe iz koncentracijskega taborišča s komentarjem (ur. Pirnovar, H.), Celje 1999, str. 104-108.

Visočnik, V., Revolucija in umetnost, Risbe iz zaporov in taborišč (ur. Visočnik, V., Bassin, A., Lakovič, V.), Nova Gorica 1969, uvodni tekst.

Weissberg, L., In Plain Sight, v: Visual Culture and the Holocaust (ur. Zelizer, B.), New Brunswick 2001, str. 13-27.

Young, J. E., At Memory's Edge, After-Images of the Holocaust in Contemporary Art and Arhitecture, New Haven 2000.

Zelizer, B., Introduction: On visualizing the Holocaust, v: Visual Culture and the Holocaust (ur. Zelizer, B.), New Brunswick 2001, str. 1-10.

Zgonik, N., Obrazi smrti, v: Videnja Zorana Mušiča (ur. Grafenauer, N., Puhar, A., Zupan, G.), Ljubljana 2012, str. 132-140.

Zupan, G., Zorenje Zorana (Antona) Mušiča med 1909 in 1935, v: Zbornik za Špelco Čopič (ur. Ilich-Klančnik, B.), Ljubljana 2006, str. 136-162.

Zupan, G., Risbe Zorana Mušiča iz taborišča Dachau, v: Zbornik za Staneta Bernika (ur. Zupan, G.), Ljubljana 2009, str. 274-301. 
Zupan, G., Življenje in ustvarjanje, v: Zoran Mušič v javnih in zasebnih zbirkah v Sloveniji (ur. Ilich Klančnik, B., Soban, T.), 24. november 2009-28. februar 2010, Moderna galerija, Ljubljana 2009, str. 191-214.

Zupan, G., Umetnikovo življenje, v: Videnja Zorana Mušiča (ur. Grafenauer, N., Puhar, A., Zupan, G.), Ljubljana 2012, str. 250-258.

Žgank, J., Poskus opredelitve pričevanjske književnosti ob besedilih francoskih in slovenskih pisateljev-deportirancev. Diplomsko delo, Ljubljana 2008. 


\section{Asta Vrečko}

\section{Problematika taboriščne umetnosti in Zoran Mušič}

Ključne besede: taboriščna umetnost, Zoran Mušič, slikarstvo, Nismo poslednji

Tematiko taborišč, holokavsta in genocida $\mathrm{v}$ umetnosti lahko najdemo pri umetnikih različnih generacij in $\mathrm{v}$ različnih medijih. Pri razmišljanju o tovrstni umetnosti se praviloma pojavijo podobne dileme in problemi. $\mathrm{K}$ umetniškim in umetnostnim vprašanjem avtorji praviloma pazljivo pristopajo, ta vprašanja navadno ostanejo v senci dilem in razmišljanj o moralni upravičenosti in zgodovinske točnosti teh umetniških del.

Umetnike, ki se ukvarjajo s taboriščno umetnostjo, lahko grobo delimo na tiste, ki so internacijo izkusili na lastni koži, in na tiste, ki je niso. Zoran Mušič (1909-2005) je eden najbolj uveljavljenih slovenskih slikarjev 20. stoletja in je preživel obe svetovni vojni ter internacijo v Dachauu. Ohranjena so njegova dela iz časa internacije, $\mathrm{k}$ taboriščni tematiki pa se je v slikarstvu vrnil šele mnogo pozneje, v sedemdesetih in osemdesetih letih 20. stoletja, v ciklusu grafik in platen s skupnim naslovom Nismo poslednji. Ta vrnitev umetnikov $\mathrm{k}$ temam taborišča po dolgem premoru ni neznačilna in jo lahko najdemo tudi pri drugih umetnikih, desetletja nastanka ciklusa Nismo poslednji pa tudi širše zaznamuje pojav spominske literature in likovne umetnosti. Mušičeva dela tega ciklusa zaznamujejo tako dovršena estetika in likovne prvine kot neposredna kruta realnost upodobljenega, kar jih naredi še dodatno zanimava tudi $\mathrm{v}$ kontekstu širše problematike tega področja. V prispevku poizkusim njegova dela iz ciklusa Nismo poslednji umestiti v širši kontekst taboriščne in pričevanjske umetnosti. 


\section{Asta Vrečko}

\section{Zoran Mušič and the Problem of Concentration Camp Art}

Keywords: camp art, Zoran Mušič, painting, We are not the last

Art that concerns itself with themes of concentration camps, the Holocaust and genocide is extremely varied. Many authors of different generations have been engaged in it in different media. And yet, similar problems and dilemmas appear in the analysis of this art. Often questions about the artistic merit of the works are secondary, being overshadows by questions about the moral justification of the existence of the work of art and its historical accuracy. Reflections on the aesthetics of these works of art turn out to be very delicate. The cycle We Are not the Last by Zoran Mušič (19092005), one of the most recognisable Slovene painters, is distinguished at once by aesthetic perfection and the immediate cruel reality of the imagery. Reflecting upon his works within the framework of concentration camp art and survivor's testimony can contribute to a better understanding of his works. 